\title{
MHD Stagnation-point Flow over a Stretching/ Shrinking Sheet in Nanofluids
}

\author{
Nor Hathirah Abd Rahman', Norfifah Bachok ${ }^{1,2, *}$, Haliza Rosali ${ }^{1}$ \\ ${ }^{1}$ Department of Mathematics, Faculty of Science, Universiti Putra Malaysia, Malaysia \\ ${ }^{2}$ Institute for Mathematical Research, Universiti Putra Malaysia, Malaysia
}

Copyright $\odot 2019$ by authors, all rights reserved. Authors agree that this article remains permanently open access under the terms of the Creative Commons Attribution License 4.0 International License

\begin{abstract}
In this study, we investigated the problem of steady two-dimensional magnetohydrodynamic (MHD) stagnation-point flow over a linearly stretching/shrinking sheet in nanofluids. There are three types of metallic nanoparticles considered such as copper $(\mathrm{Cu})$, alumina $\left(\mathrm{Al}_{2} \mathrm{O}_{3}\right)$ and titania $\left(\mathrm{TiO}_{2}\right)$ in the base fluid of water with the Prandtl number $P r=6.2$ to investigate the effect of the nanoparticles volume fraction parameter $\varphi$ of the nanofluids. In this problem, the governing nonlinear partial differential equations are transformed into the nonlinear ordinary differential equations by using a similarity transformation and then solved numerically using the boundary value problems solver bvp4c in Matlab software. The influence of magnetic field parameter, $M$ on the skin friction coefficient $C_{f}$, local Nusselt number $N u$ and the velocity and temperature profiles are presented graphically and discussed. The results show that the velocity and temperature are influenced by the magnetic field and nanoparticles volume fraction. The dual solutions exist for shrinking sheet case and the solutions are non-unique, different from a stretching sheet. The numerical values of $C_{f} R e_{x}^{1 / 2}$ and $N u_{x} R e_{x}^{-1 / 2}$ for $M=0$ are also computed, which show a favourable agreement with previous work.
\end{abstract}

Keywords Magnetohydrodynamic, Stagnation-point Flow, Stretching/Shrinking Sheet, Nanofluids, Dual Solutions

\section{Introduction}

In the boundary layer problem, the stagnation-point flow effect has been attracted the interest of many researchers due to its applications in industry such as flows over the tips of aircraft, submarines, etc. Stagnation-point flow is the fluid motion near the stagnation region of a solid surface exists in both cases of a fixed or moving body in a fluid. Hiemenz [1] was the first researcher who studied the steady two-dimensional stagnation-point flow towards a stationary semi-infinite wall and obtained an exact solution of the governing Navier-Stokes equations. Then, the problem has been extended to the axisymmetric stagnation-point flow case by Homann [2]. Mahapatra and Gupta [3-4] have been investigated the heat transfer in the stagnation-point flow over a stretching surface through a viscoelastic fluid, respectively. Wang [5] who is the first introduced the flow past a shrinking sheet by considering both two-dimensional and axisymmetric cases of stagnation-point flow. The unique and dual solutions are obtained for shrinking parameter. Ishak et al. [6], Bhattacharyya and Layek [7], Bhattacharyya [8], Bachok et al. [9], and Lok et al. [10] have extended the work by Wang [5] by focusing different effect characteristics such as the thermal radiation, homogeneous-heterogeneous reactions and magnetic fields effect.

All the studies mentioned above are focused on stagnation-point flow towards a stretching/shrinking sheet in a viscous fluid (Newtonian fluid). Bachok et al. [11] have been investigated the problem on steady two-dimensional stagnation-point flow towards stretching/shrinking sheet in a nanofluid. They found that, the solutions are non-unique for shrinking sheet, but unique for stretching sheet. A nanofluids is a new kind of heat transfer fluids containing small quantity of nanosized particles (less than 100nm). Nanofluids solutions are obtained while dispersing in a basic fluid of the solid particles of nanometric size. The effectiveness of the transport of heat to improve had been proved by some of these solutions with very weak concentration, under certain conditions. However, the addition of nanoparticles to a basic fluid can enhance its thermal conductivity as reported by Choi et al. [12]. Choi [13] had proposed the term "nanofluid" which is to indicate the suspension of the solid nanoparticles in a basic liquid. He found that $20 \%$ increase of the effective thermal conductivity of the water- $\mathrm{Al}_{2} \mathrm{O}_{3}$ mixture for a volume fraction from 1 to $5 \%$ of $\mathrm{Al}_{2} \mathrm{O}_{3}$. Therefore, Choi [13] and Masuda et al. [14] have shown that it is possible to break down the limits of conventional solid particle suspensions by conceiving the concept of 
nanoparticle-fluid suspensions.

It is accepted that boundary layer flow gets influences by magnetohydrodynamic (MHD). It is described as a branch of fluid dynamics which deals the movement of an electrically conducting fluid in the presence of a magnetic field. Rashidi et al. [15], Sandeep and Sulochana [16], Soid et al. [17], Ishak et al. [18] and Mahapatra and Gupta [19] have studied the MHD flow of stagnation-point in viscous fluid over stretching and shrinking sheet. While, Hamad [20] has analysed the convective flow of heat transfer past a semi-infinite vertical stretching sheet with the magnetic field effect in nanofluid. Hsiao [21], Makinde et al. [22], Mami and Bouaziz [23], Nandy and Mahapatra [24] and Nayak et al. [25] also have investigated the effect of MHD in nanofluids with the presence of other effects such as slip and thermal radiation.

In this paper, we extend the work of Bachok et al. [11] by including the effect of magnetic field (MHD) on the problem of steady stagnation-point flow over a stretching/shrinking sheet in nanofluids by using Tiwari and Das [26] model. Mansur et al. [27] have studied this problem in the presence of suction effect by using Buongiorno [28] model. There are two models that have been constantly used by researchers to study the behavior of nanofluids which are Buongiorno [28] and Tiwari and Das [26] models. Here the Buongiorno [28] model highlights on the Brownian motion and thermophoresis on the heat transfer characteristics, whereas Tiwari and Das [26] model focuses on the solid volume fraction of nanofluids. The effects of the magnetic field, solid volume fraction and the type of nanoparticles on characteristics of energy flow will be studied numerically and discussed further. For some particular cases of the present study, the results are compared with Bachok et al. [11] to support their validity.

\section{Materials and Methods}

Considering a steady, incompressible, laminar, two-dimensional magnetohydrodynamic (MHD) stagnation-point flow over a stretching/shrinking sheet in a water-based nanofluid contains different types of nanoparticles such as $\mathrm{Cu}, \mathrm{Al}_{2} \mathrm{O}_{3}$, and $\mathrm{TiO}_{2}$ that located at the plane $y=0$, and confined at region $y>0$. It is assumed that, the stretching/shrinking velocity $U_{w}(x)=$ $a x$ and the ambient fluid velocity $U_{\infty}(x)=b x$ to vary linearly to the distance $x$ from the stagnation point, where $b$ is a positive constant and $a$ is a constant with $a>0$ and $a<0$ corresponds to stretching and shrinking sheet respectively. Furthermore, a transverse magnetic field strength $B_{0}$ is applied normal to the sheet with constant electrical conductivity $\sigma$. The induced magnetic field is neglected due to the small value of magnetic Reynolds number. Therefore, the simplified two-dimensional MHD govern equations for the steady, laminar and incompressible nanofluid are

$$
\begin{gathered}
\frac{\partial u}{\partial x}+\frac{\partial v}{\partial y}=0 \\
u \frac{\partial u}{\partial x}+v \frac{\partial u}{\partial y}=U_{\infty} \frac{d U_{\infty}}{d x}+\frac{\mu_{n f}}{\rho_{n f}} \frac{\partial^{2} u}{\partial y^{2}}+\frac{\sigma B_{0}^{2}}{\rho_{n f}}\left(U_{\infty}-u\right) \\
u \frac{\partial T}{\partial x}+v \frac{\partial T}{\partial y}=\alpha_{n f} \frac{\partial^{2} T}{\partial y^{2}}
\end{gathered}
$$

along with the initial and boundary conditions,

$$
\begin{gathered}
u=U_{w}(x), v=0, T=T_{w} \text { at } y=0, \\
u \rightarrow U_{\infty}(x), T \rightarrow T_{w} \text { as } y \rightarrow \infty
\end{gathered}
$$

where $u$ and $v$ are the velocity components along the $x$ and $y$-axes, respectively. Then, $\mu_{n f}, \rho_{n f}, \alpha_{n f}$ and $T$ are viscosity of the nanofluid, density of the nanofluid, thermal diffusivity of the nanofluid and temperature of the nanofluid, which are given by Oztop and Abu Nada [29] as

$$
\begin{gathered}
\alpha_{n f}=\frac{k_{n f}}{\left(\rho C_{p}\right)_{n f}}, \rho_{n f}=(1-\varphi) \rho_{f}+\varphi \rho_{s}, \mu_{n f}=\frac{\mu_{f}}{(1-\varphi)^{2.5}}, \\
\left(\rho C_{p}\right)_{n f}=(1-\varphi)\left(\rho C_{p}\right)_{f}+\varphi\left(\rho C_{p}\right)_{s}, \\
\frac{k_{n f}}{k_{f}}=\frac{\left(k_{s}+2 k_{f}\right)-2 \varphi\left(k_{f}-k_{s}\right)}{\left(k_{s}+2 k_{f}\right)+\varphi\left(k_{f}-k_{s}\right)}
\end{gathered}
$$

where $\varphi$ is the nanoparticle volume fraction parameter of the nanofluid, $k_{n f}$ is the thermal conductivity of the fluid fraction, $k_{s}$ is the thermal conductivity of the nanoparticle volume fraction, $\rho_{f}$ is the reference density of the fluid fraction, $\rho_{s}$ is the reference density of solid fraction, $\mu_{f}$ is viscosity of the fluid fraction, and $\left(\rho C_{p}\right)_{n f}$ is the heat capacitance of the nanofluids, where $C_{p}$ is the specific heat at constant pressure. The viscosity of the nanofluid $\mu_{n f}$ has been approximated by Brinkman [30] as viscosity of the base fluid $\mu_{f}$ containing dilute suspension of fine spherical particles.

To obtain a similarity solution for momentum and energy equations (1) - (3), the similarity transformations (Bachok et al. [11]) are introduced:

$$
\eta=\left(\frac{b}{v_{f}}\right)^{\frac{1}{2}} y, \psi=\left(v_{f} b\right)^{\frac{1}{2}} x f(\eta), \theta(\eta)=\frac{T-T_{\infty}}{T_{w}-T_{\infty}}
$$

where a stream function $\psi$ is defined as $u=\partial \psi / \partial y$ and $v=-\partial \psi / \partial x$ which identically satisfied with the continuity equation (1). Then, $T_{w}$ is the temperature of the fluid at the stretching/shrinking sheet and $T_{\infty}$ is the temperature of the fluid far away from the stretching/shrinking sheet. By substituting variables (6) into (2) and (3), the transformed ordinary differential equations are obtained:

$$
\begin{gathered}
\frac{1}{(1-\varphi)^{2.5}\left(1-\varphi+\frac{\varphi \rho_{s}}{\rho_{f}}\right)} f^{\prime \prime \prime}+f f^{\prime \prime}-f^{\prime 2}+1+ \\
M\left(1-f^{\prime}\right)=0, \\
\frac{1}{\operatorname{Pr}} \frac{k_{n f} / k_{f}}{\left[1-\varphi+\varphi\left(\rho C_{p}\right)_{s} /\left(\rho C_{p}\right)_{f}\right]} \theta^{\prime \prime}+f \theta^{\prime}=0,
\end{gathered}
$$

subjected to the boundary conditions (4) which become 


$$
\begin{aligned}
& f(0)=0, f^{\prime}(0)=\varepsilon, \theta(0)=1, \\
& f^{\prime}(\eta) \rightarrow 1, \theta(\eta) \rightarrow 0 \text { as } \eta \rightarrow \infty .
\end{aligned}
$$

Here, the prime notations in (7) - (9) are denoting the differentiation with respect to $\eta$. Hence, $\operatorname{Pr}=v_{f} / \alpha_{f}$ is the Prandtl number, $M=\sigma B_{0}^{2} /\left(\rho_{f} b\right)$ is the magnetic field parameter and $\varepsilon=a / b$ is the velocity ratio parameter where $\varepsilon>0$ for stretching and $\varepsilon<0$ for shrinking.

The physical quantities of interest are the skin friction coefficient $C_{f}$ and the local Nusselt number $N u_{x}$, which are defined as

$$
C_{f}=\frac{\tau_{w}}{\rho_{f} U_{\infty}^{2}}, N u_{x}=\frac{x q_{w}}{k_{f}\left(T_{w}-T_{\infty}\right)},
$$

where the surface shear stress $\tau_{w}$ and the surface heat flux $q_{w}$ are given by

$$
\tau_{w}=\mu_{n f}\left(\frac{\partial u}{\partial y}\right)_{y=0}, q_{w}=-k_{n f}\left(\frac{\partial T}{\partial y}\right)_{y=0},
$$

with $\mu_{n f}$ and $k_{n f}$ being dynamic viscosity and thermal conductivity of the nanofluids, respectively. Using the similarity variables (6), we obtain

$$
\begin{gathered}
C_{f} R e_{x}^{1 / 2}=\frac{1}{(1-\varphi)^{2.5}} f^{\prime \prime}(0), \\
N u_{x} / R e_{x}^{1 / 2}=-\frac{k_{n f}}{k_{f}} \theta^{\prime}(0),
\end{gathered}
$$

where $R e_{x}=U_{\infty} x / v_{f}$ is the local Reynolds number.

\section{Results and Discussion}

The nonlinear ordinary differential equations (7) and (8) subjected to the boundary conditions (9) have been solved numerically using the function bvp $4 \mathrm{c}$ from Matlab due to its effectiveness in solving the boundary value problems which are much harder than initial value problems. By setting different initial guesses for the missing values for $f^{\prime \prime}(0)$ and $\theta^{\prime}(0)$, the dual solutions were obtained. The guess must satisfy the boundary conditions (9) asymptotically, thus keep the behaviour of the solution. The effects of nanoparticles volume fraction of nanofluid $\varphi$, the Prandtl number $\operatorname{Pr}$ and the magnetic field parameter $M$ are analysed for three different types of nanofluids which are copper $(\mathrm{Cu})$, alumina $\left(\mathrm{Al}_{2} \mathrm{O}_{3}\right)$ and titania $\left(\mathrm{TiO}_{2}\right)$ as the working fluids and water as the base working fluid. The Prandtl number is taken to be $P r=6.2$ and nanoparticles volume fraction is considered from 0 to 0.2 $(0 \leq \varphi \leq 0.2$ ), where $\varphi=0$ corresponding to the regular fluid. The thermophysical properties of the base fluid and the nanoparticles are listed in Table 1 . The numerical values of $C_{f} R e_{x}^{1 / 2}$ and $N u_{x} R e_{x}^{-1 / 2}$ for $M=0$ are also computed, which show a favourable agreement with previous work by Bachok et al. [11]. The numerical computations were performed for several values of the stretching/shrinking parameter $\varepsilon$, magnetic field parameter $M$ and nanoparticles volume fraction for further research.
Table 1 Thermophysical properties of fluid and nanoparticles (Oztop and Abu Nada [29])

\begin{tabular}{ccccc}
\hline $\begin{array}{c}\text { Physical } \\
\text { properties }\end{array}$ & Fluid phase (water) & $\mathrm{Cu}$ & $\mathrm{Al}_{2} \mathrm{O}_{3}$ & $\mathrm{TiO}_{2}$ \\
\hline$C_{p}(\mathrm{~J} / \mathrm{kg} \mathrm{K})$ & 4179 & 385 & 765 & 686.2 \\
\hline$\rho\left(\mathrm{kg} / \mathrm{m}^{3}\right)$ & 997.1 & 8933 & 3970 & 4250 \\
\hline$k(\mathrm{~W} / \mathrm{mK})$ & 0.613 & 400 & 40 & 8.9538
\end{tabular}

Figures 1, 2, 3 and 4 illustrate the variation of skin friction $f^{\prime \prime}(0)$ and local Nusselt number $-\theta^{\prime}(0)$ for some values of the magnetic field parameter $M$ and nanoparticles volume fraction $\varphi$ towards stretching/shrinking parameter. From these figures, we can observe that, the unique solutions are forms in region $\varepsilon>$ -1 , the dual solutions are exist in the region $\varepsilon_{c}<\varepsilon \leq-1$ and no solutions for $<\varepsilon_{c}<0$, where $\varepsilon_{c}$ is the critical value of $\varepsilon$. From this observation, Bachok et al [11] stated that, the first solution is stable and physically realizable, while second solution is not stable. The value of $f^{\prime \prime}(0)$ is zero when $\varepsilon=1$ in the Figures 1 and 3 because the friction does not occur at the fluid-solid interface when both fluid and solid boundary move with the same velocity. The positive value of $f^{\prime \prime}(0)$ when $\varepsilon<1$ means that the fluid exerts a drag force on the solid boundary and negative value when $\varepsilon>1$ means the opposite.

The variations of the skin friction coefficient and the local Nusselt number with different nanoparticles; namely copper $(\mathrm{Cu})$, alumina $\left(\mathrm{Al}_{2} \mathrm{O}_{3}\right)$ and titania $\left(\mathrm{TiO}_{2}\right)$ with different values of magnetic field parameter $M(M=$ $0,0.1,0.2$ ) are shown in Figures 5 and 6. These quantities increase almost linearly with $\varphi$. From these figures, we can state that, the increasing of the magnetic field parameter $M$ will increase the both value of skin friction and Nusselt number coefficient. These figures show that $\mathrm{Al}_{2} \mathrm{O}_{3}$ has the lowest skin friction coefficient and the difference values between $\mathrm{TiO}_{2}$ and $\mathrm{Al}_{2} \mathrm{O}_{3}$ are very small. However, $\mathrm{TiO}_{2}$ has the lowest heat transfer rate compared to $\mathrm{Cu}$ and $\mathrm{Al}_{2} \mathrm{O}_{3}$ due to the domination of conduction mode of heat transfer. Table 1 clearly shows that $\mathrm{TiO}_{2}$ has the lowest value of thermal conductivity compared to $\mathrm{Cu}$ and $\mathrm{Al}_{2} \mathrm{O}_{3}$.

Further, Figures $7-12$ physically show the velocity and temperature profiles for different values of $\varphi, M$ and nanoparticles which support the existence of dual solution in Figures 1-4 for certain values of $\varepsilon$. Figure 7 indicates that, the increasing of $M$, increase the velocity profiles at any point $\eta$ except at the sheet where the boundary conditions confine it to value 1.0. Figure 9 shows that the momentum boundary layer increases as $\varphi$ increase. However, Figure 10 shows that the thermal boundary layer thickness increases with a decrease in the parameter $\varphi . \mathrm{Cu}$ has the highest momentum boundary layer and lowest thermal boundary layer thickness compared to the $\mathrm{Al}_{2} \mathrm{O}_{3}$ and $\mathrm{TiO}_{2}$ as shown in the Figures 11 and 12. As we observed, the boundary layer thickness for the first solution is thicker than the second solution. It can be seen that all these profiles are asymptotically satisfied all boundary conditions (9) thus support the validity of the numerical results as well as existence of the dual solutions. 


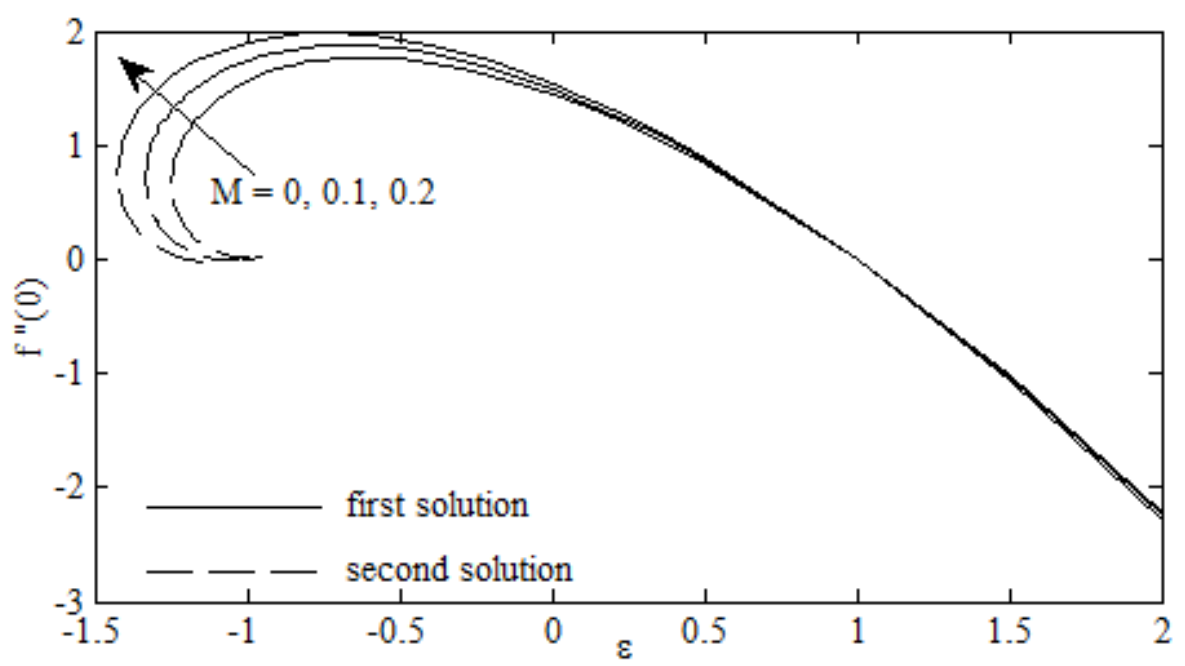

Figure 1. Variation of $f^{\prime \prime}(0)$ with $\varepsilon$ for some values of $M$ for Cu-water working fluid, $\operatorname{Pr}=6.2$ and $\varphi=0.1$

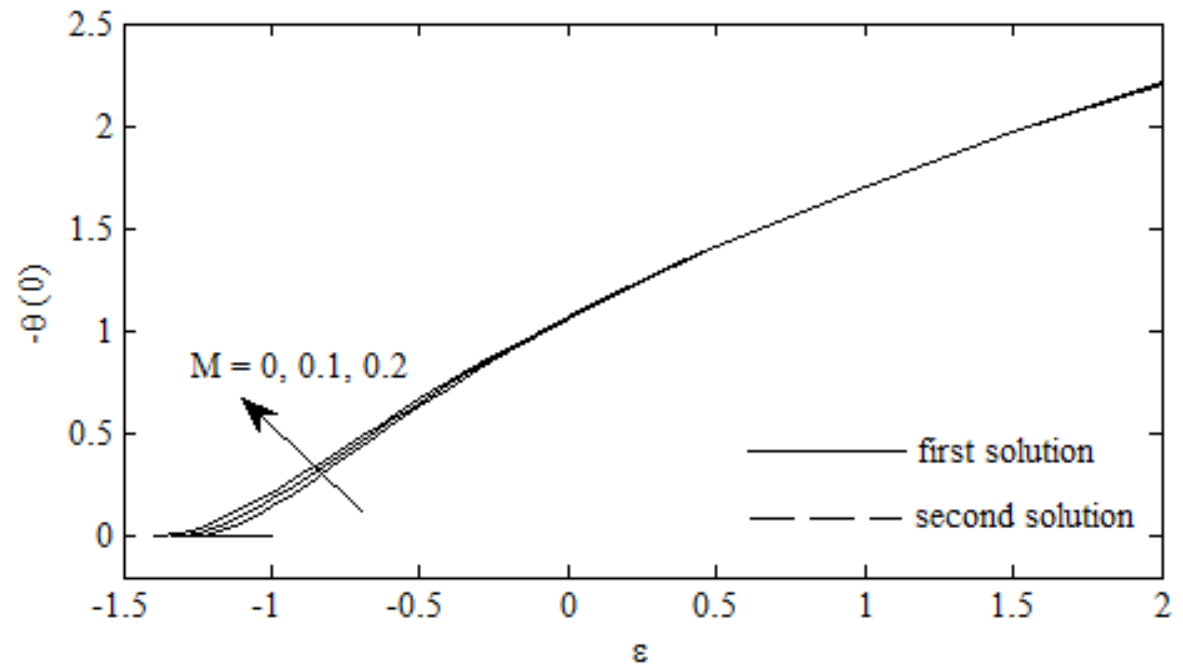

Figure 2. Variation of $-\theta^{\prime}(0)$ with $\varepsilon$ for some values of $M$ for $\mathrm{Cu}$-water working fluid, $\operatorname{Pr}=6.2$ and $\varphi=0.1$

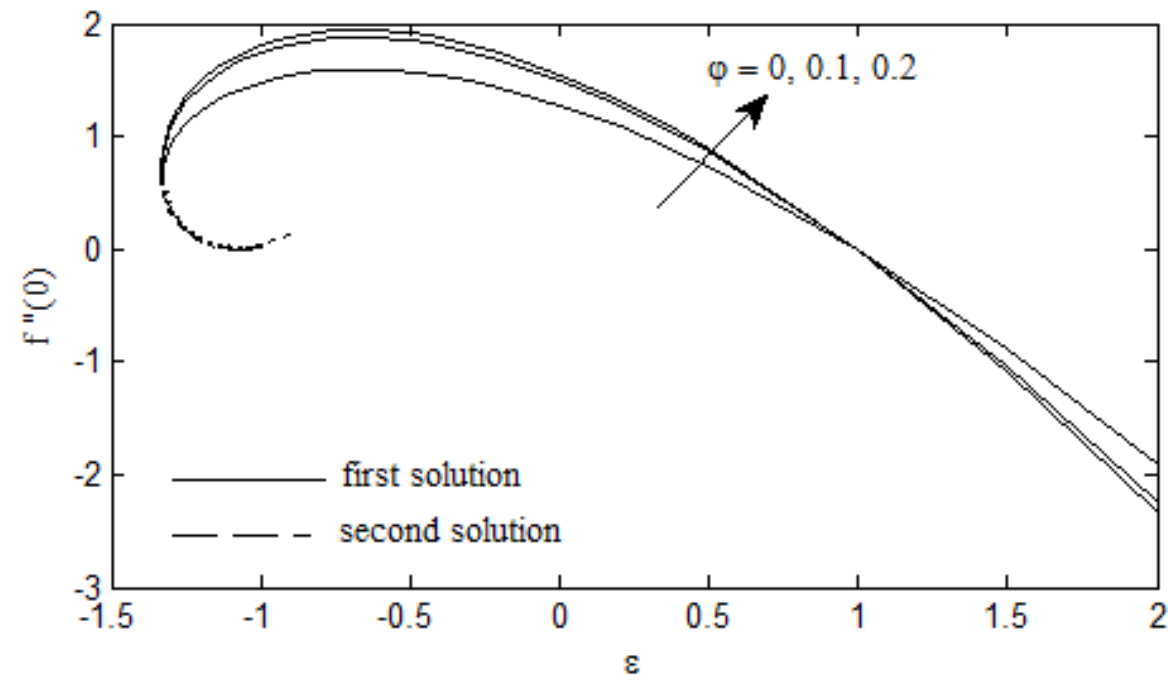

Figure 3. Variation of $f^{\prime \prime}(0)$ with $\varepsilon$ for some values of $\varphi(0 \leq \varphi \leq 0.2)$ for $\mathrm{Cu}$-water working fluid, $\operatorname{Pr}=6.2$ and $M=0.1$ 


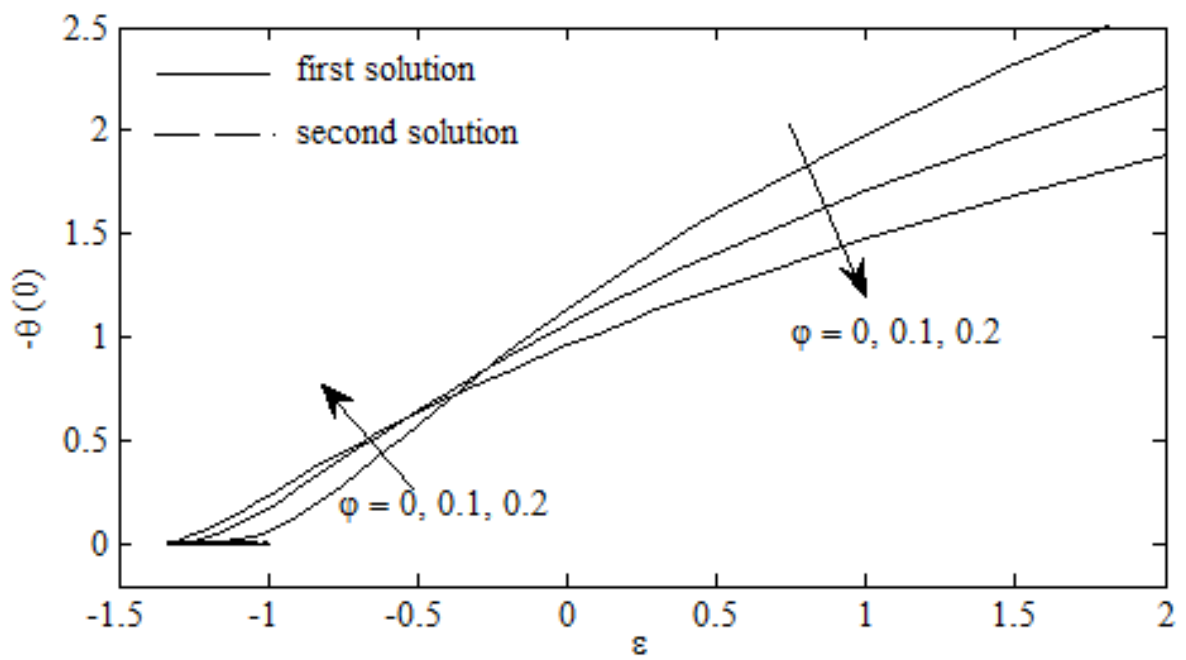

Figure 4. Variation of $-\theta^{\prime}(0)$ with $\varepsilon$ for some values of $\varphi(0 \leq \varphi \leq 0.2)$ for Cu-water working fluid, $\operatorname{Pr}=6.2, M=0.1$

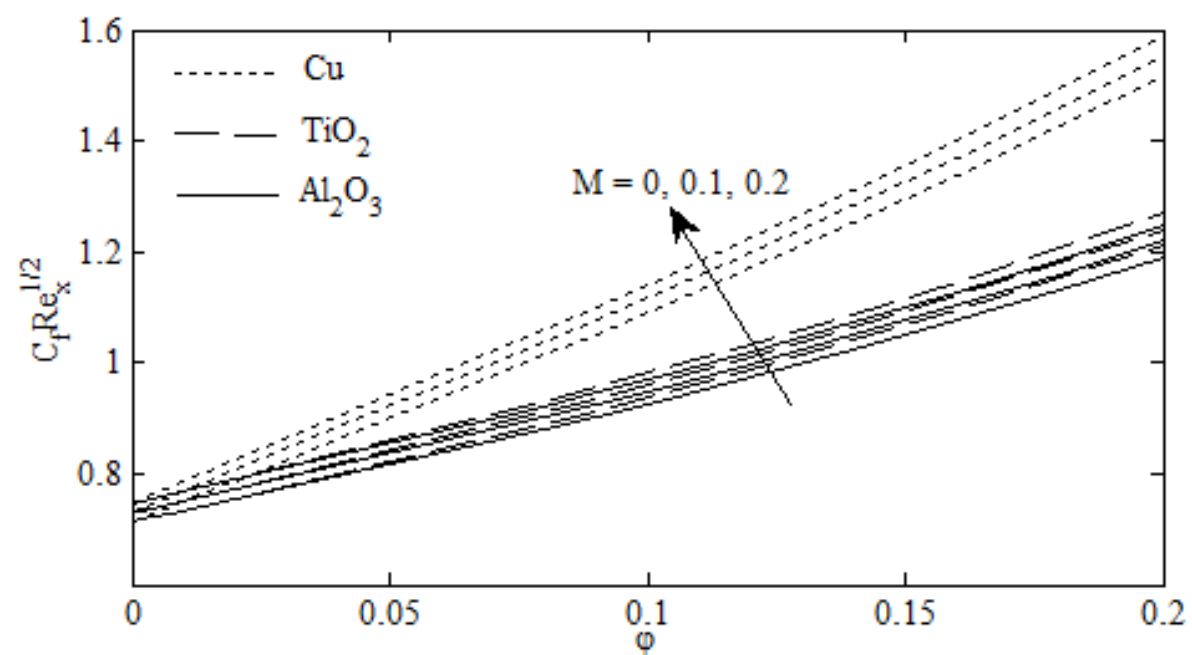

Figure 5. Variation of the skin friction coefficient $C_{f} R e_{x}^{1 / 2}$ with $\varphi$ for different nanoparticles and magnetic field $M$ with $\varepsilon=0.5$ and $\operatorname{Pr}=6.2$

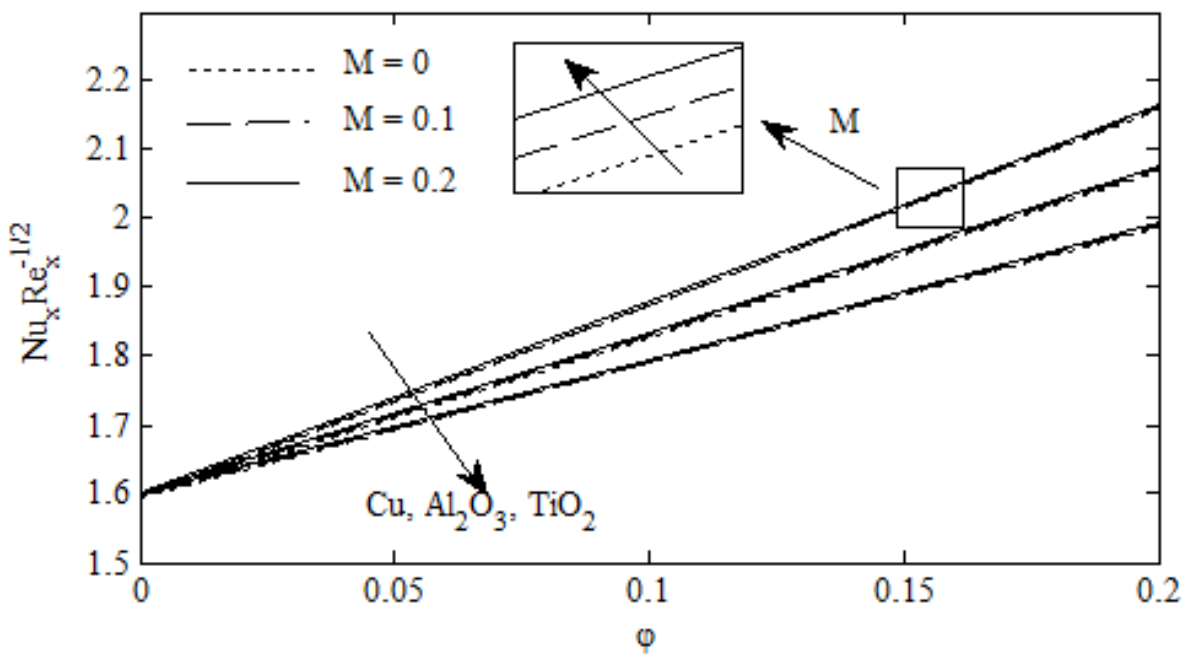

Figure 6. Variation of the local Nusselt number $N u_{x} R e_{x}^{-1 / 2}$ with $\varphi$ for different nanoparticles and magnetic field $M$ with $\varepsilon=0.5, P r=6.2$ 


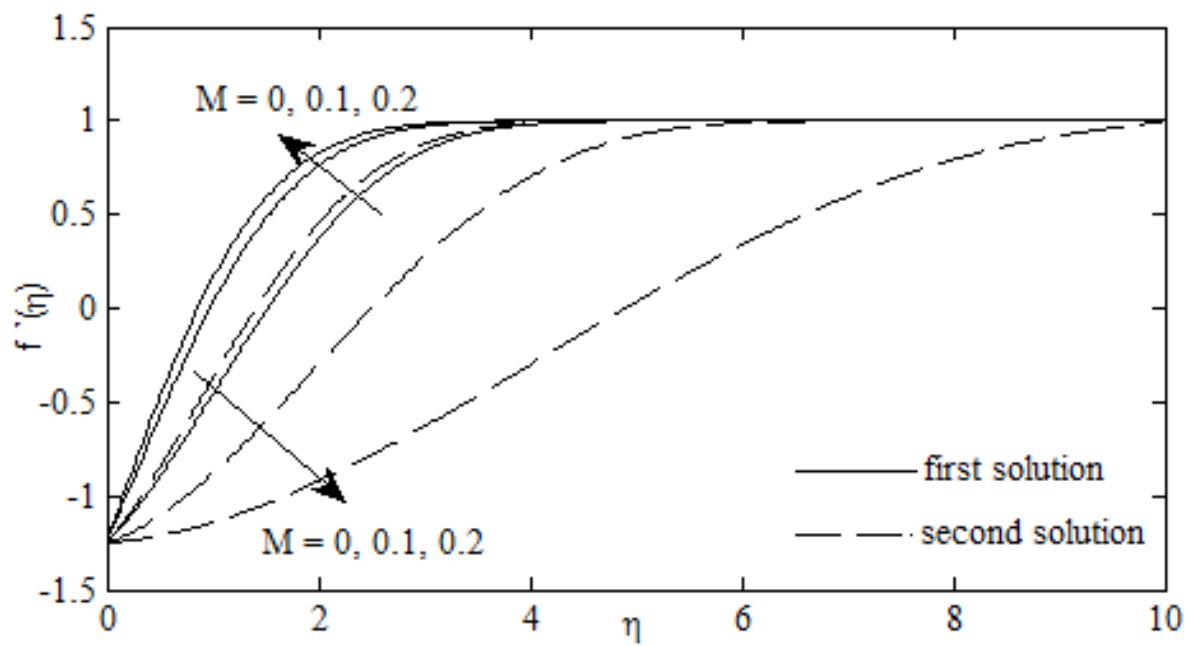

Figure 7. Velocity profiles for different $M$ for Cu-water working fluid with $\varphi=0.1, \varepsilon=-1.25$ and $\operatorname{Pr}=6.2$

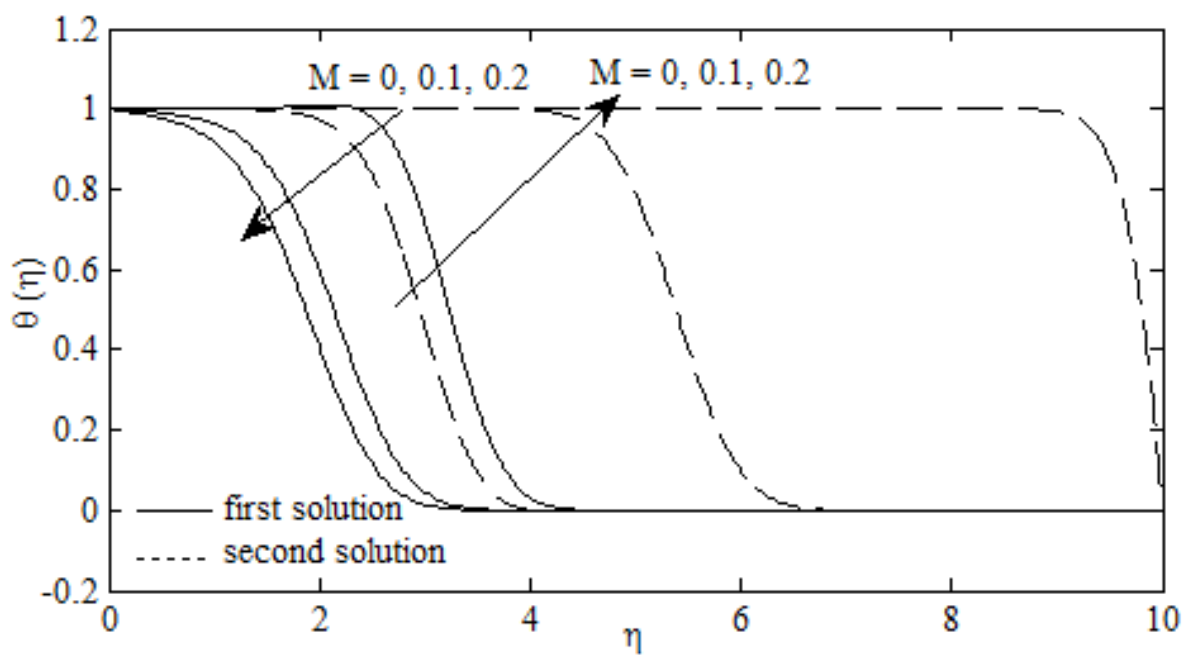

Figure 8. Temperature profiles for different $M$ for $\mathrm{Cu}$-water working fluid with $\varphi=0.1, \varepsilon=-1.25$ and $\operatorname{Pr}=6.2$

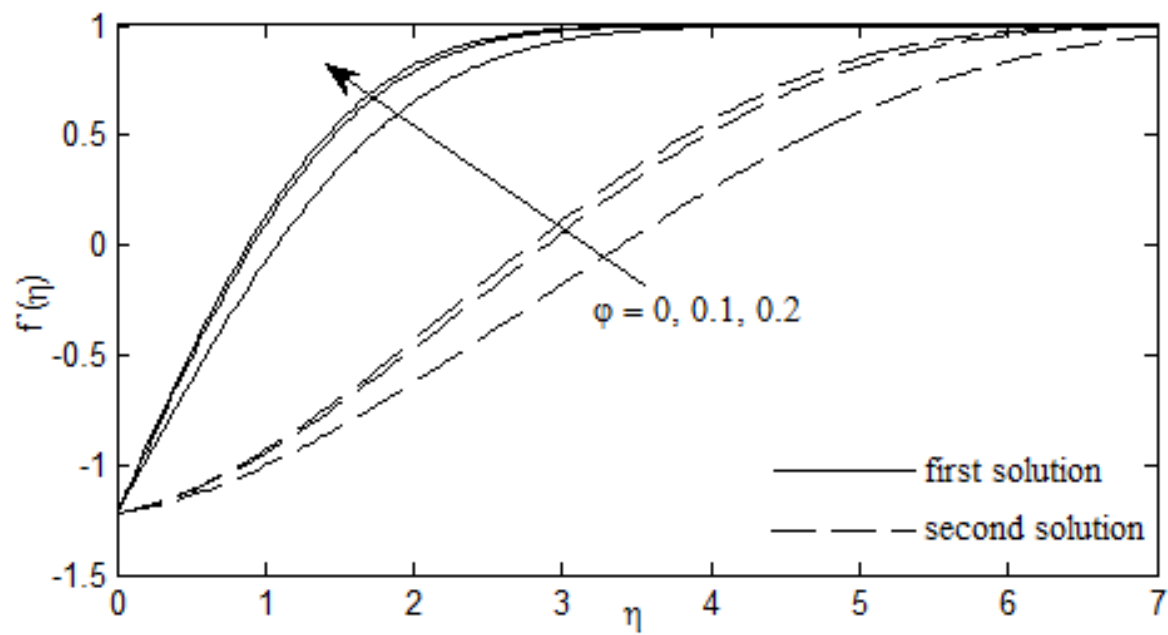

Figure 9. Velocity profiles for some values of $\varphi(0 \leq \varphi \leq 0.2)$ for $\mathrm{Cu}$-water working fluid with $\varepsilon=-1.22, \operatorname{Pr}=6.2$ and $M=0.1$ 


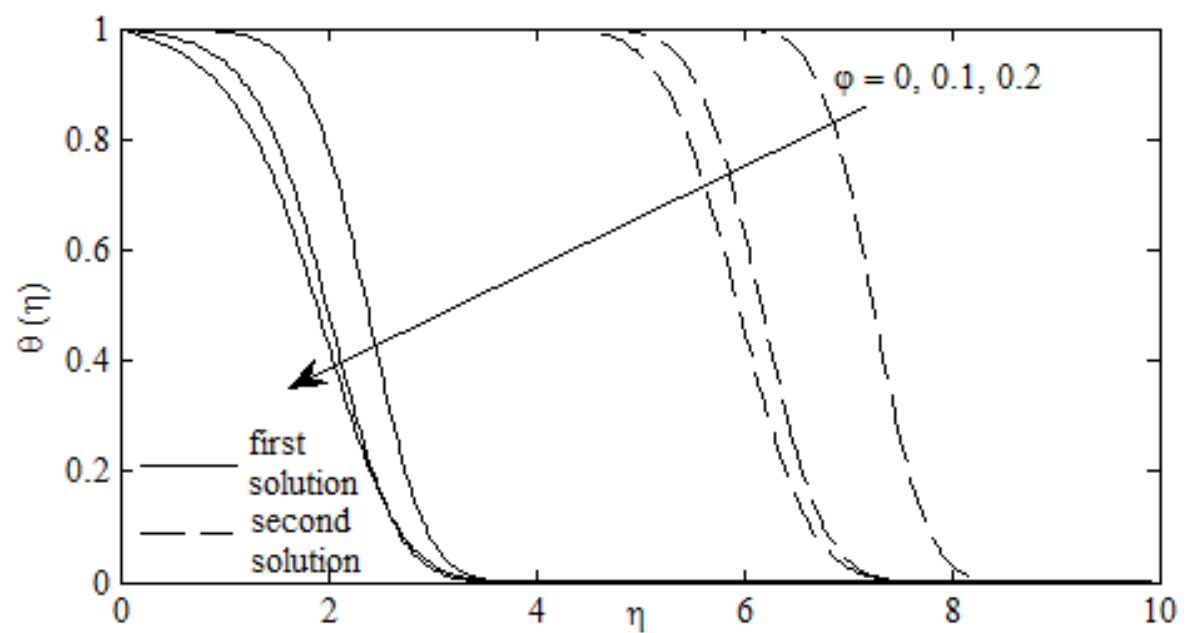

Figure 10. Temperature profiles for some values of $\varphi(0 \leq \varphi \leq 0.2)$ for Cu-water working fluid with $\varepsilon=-1.22, \operatorname{Pr}=6.2$ and $M=0.1$

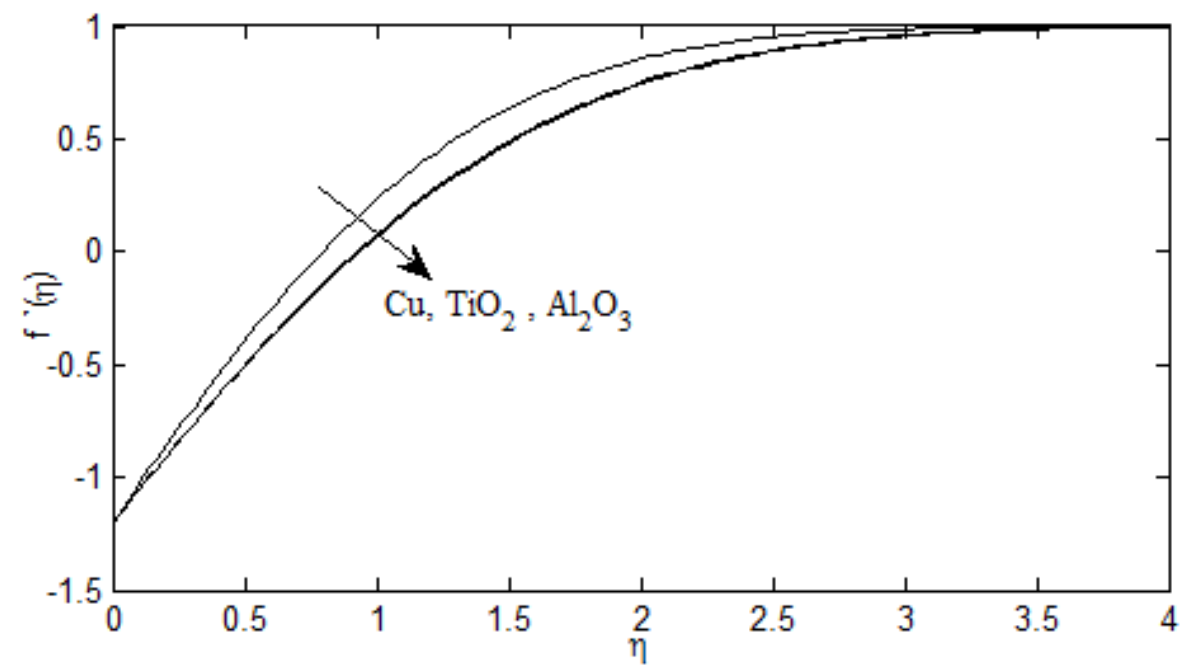

Figure 11. Velocity profiles for different nanoparticles with $\varphi=0.1, \varepsilon=-1.2, M=0.2$ and $\operatorname{Pr}=6.2$

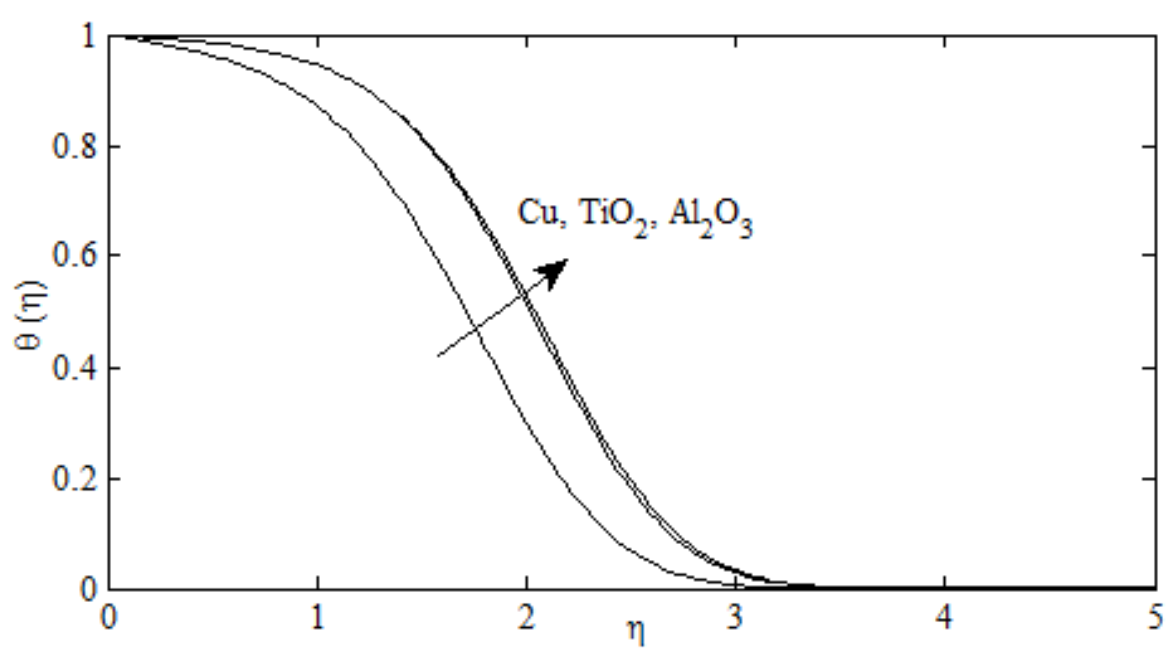

Figure 12. Temperature profiles for different nanoparticles with $\varphi=0.1, \varepsilon=-1.2, M=0.2$ and $\operatorname{Pr}=6.2$ 


\section{Conclusions}

We have numerically analysed how magnetic field parameter $M$ affects the flow of stagnation-point over stretching/shrinking sheet in nanofluids. From the stagnation-point distance, the stretching/shrinking and the ambient fluid velocities are assumed to vary linearly. The analysis effect of nanoparticles volume fraction parameter $\varphi$ and heat transfer characteristics for three types of nanoparticles which are copper $(\mathrm{Cu})$, alumina $\left(\mathrm{Al}_{2} \mathrm{O}_{3}\right)$ and titania $\left(\mathrm{TiO}_{2}\right)$ were solved numerically in water-based fluid with Prandtl number $P r=6.2$. As the magnetic field parameter $M$ increases, the skin friction coefficient and heat transfer rate increase. The dual solutions are found for the shrinking sheet while only unique solution for the stretching sheet. With the increment of the magnetohydrodynamic, the range of solutions is widely expanded.

\section{Acknowledgements}

The authors gratefully acknowledge the financial support received in the form of a fundamental research grant scheme (FRGS/1/2018/STG06/UPM/02/4/5540155). Lastly, humbly and sincerely appreciate all the reviewers for their honest feedback and suggestions.

\section{REFERENCES}

[1] K. Hiemenz. Die Grenzschicht an einem in den gleichförmigen Flüssigkeitsstrom eingetauchten geraden Kreiszylinder, Dingler's Polytech J, 326, 321-324, 1911.

[2] F. Homann. Der Einfluss grosser Zahigkeit bei der Stromung um den Zylinder und um die Kugel, Z Angew Math Mech, Vol.16, 153-164, 1936.

[3] T. R. Mahapatra, A. S. Gupta. Heat transfer in stagnation-point flow towards a stretching sheet, Heat Mass Tran, Vol.38, 517-521, 2002.

[4] T. R. Mahapatra, A. S. Gupta Stagnation-point flow towards a stretching surface, Can J Chen Eng, Vol.81, 258-263, 2003.

[5] C. Y. Wang. Stagnation flow towards a shrinking sheet, Int J Non Lin Mech, Vol.43, 377-382, 2008.

[6] A. Ishak, Y. Y. Lok, I. Pop. Stagnation-point flow over a shrinking sheet in a micropolar fluid, Chem Eng Commun Vol.197, 1417-1427, 2010.

[7] K. Bhattacharyya, G. C. Layek. Efforts of suction/blowing on steady boundary layer stagnation-point flow and heat transfer towards a shrinking sheet with thermal radiation, Int J Heat Mass Trans, Vol.54, 302-307, 2011.

[8] K. Bhattacharyya. Heat transfer analysis in unsteady boundary layer stagnation-point flow towards a shrinking/stretching sheet, Ain Shams Engineering Journal,
Vol.4, 259-264, 2013.

[9] N. Bachok, A. Ishak, I. Pop. On the stagnation-point flow towards a stretching sheet with homogeneous-heterogeneous reactions effects, Comm Nonlinear Sci Numer Simulat, Vol.16, 4296-4302, 2011.

[10] Y. Y. Lok, A. Ishak, I. Pop. MHD stagnation-point flow towards a shrinking sheet, Int $\mathrm{J}$ Numer Meth Heat Fluid Flow, Vol.21, 61-72, 2011.

[11] N. Bachok, A. Ishak, I. Pop. Stagnation-point flow over a stretching/shrinking sheet in a nanofluid, Nanoscale Research Letters, Vol.6, 623, 2011.

[12] S. U. S. Choi, Z. G. Zhang, W. Yu, F. E. Lockwood, E. A. Grulke. Anomalously thermal conductivity enhancement in nano-tube suspensions, Applied Physics Letters, Vol.79, 2252-2254, 2001.

[13] S. Choi. Enhancing thermal conductivity of fluids with nanoparticles, ASME-Publications-Fed, Vol.231, 99-106, 1995.

[14] H. Masuda, A. K. T. Ebata, N. Hishinuma. Alteration of thermal conductivity and viscosity of liquid by dispersing ultra-fine particles (dispersion of $y-\mathrm{Al}_{2} \mathrm{O}_{3}, \mathrm{SiO}_{2}$ and $\mathrm{TiO}_{2}$ ultra-fine particles), Netsu Bussei (Japan), Vol.4, No.4, 227-233, 1993.

[15] M. M. Rashidi, B. Rostami, N. Freidoonimehr, S. Abbasbandy. Free convective heat and mass transfer for MHD fluid flow over a permeable vertical stretching sheet in the presence of the radiation and buoyancy effects, Ain Shams Engineering Journal, Vol.5, 901-912, 2014.

[16] N. Sandeep, C. Sulochana. Dual solutions for unsteady mixed convection flow of MHD micropolar fluid over a stretching/shrinking sheet with non-uniform heat source/sink, Engineering Science and Technology, an International Journal, Vol.18, 738-745, 2015.

[17] S. K. Soid, A. Ishak, I. Pop. MHD stagnation point flow over a stretching/shrinking sheet, International Symposium on Mathematical Sciences \& Computing Research (iSMC) 2015 (iSMC 15), 2015.

[18] A. Ishak, K. Jafar, R. Nazar, I. Pop. MHD stagnation-point flow towards a stretching sheet, Physic A, Vol.388, 3377-3383, 2009.

[19] T. R. Mahapatra, A. S. Gupta. Magnetohydrodynamic stagnation-point flow towards a stretching sheet, Acta Mechanica, Vol.152, 191-196, 2001.

[20] M. A. A. Hamad. Analytical solution of natural convection flow of a nanofluid over a stretching sheet in the presence of magnetic field, International Communications in Heat and Mass Transfer, Vol.38, 487-492, 2011.

[21] K. L. Hsiao. Stagnation electrical MHD nanofluid mixed convection with slip boundary on a stretching sheet, Applied Thermal Engineering, Vol.98, 850-861, 2016.

[22] O. D. Makinde, W. A. Khan, Z. H. Khan. Buoyancy effects on MHD stagnation point flow and heat transfer of a nanofluid past a convectively heated stretching/shrinking sheet, International Journal of Heat and Mass Transfer, Vol.62, 526-533, 2013.

[23] N. Mami, M. N. Bouaziz. Effects of MHD on nanofluid flow, 
heat and mass transfer over a stretching surface embedded in a porous medium, Periodica Polytechnica Mechanical Engineering, Vol.62, No.2, 91-100, 2018.

[24] S. K. Nandy, T. R. Mahapatra. Effects of slip and heat generation/absorption on MHD stagnation point flow of nanofluid past a stretching/shrinking surface with convective boundary conditions, International Journal of Heat and Mass Transfer, Vol.64, 1091-1100, 2013.

[25] M. K. Nayak, N. S. Akbar, V. S. Pandey, Z. H. Khan, D. Tripathi. 3D free convective MHD flow of nanofluid over permeable linear stretching sheet with thermal radiation, Powder Technology, Vol.315, 205-215, 2017.

[26] R. Tiwari, M. Das. Heat transfer augmentation in a two-sided lid-driven differentially heated square cavity utilizing nanofluids, International Journal of Heat and Mass Transfer, Vol.50, 2002-2018, 2007.

[27] S. Mansur, A. Ishak, I. Pop. The magnetohydrodynamic stagnation point flow of a nanofluid over a stretching/shrinking sheet with suction, PLoS ONE, Vol.10, No.3:e0117733, 2015.

[28] J. Buongiorno. Convective transport in nanofluids, Journal of Heat Transfer, Vol.128, 240-250, 2006.

[29] H. Oztop, E. Abu-Nada. Numerical study of natural convection in partially heated rectangular enclosures filled with nanofluids, Int J Heat Fluid Flow, Vol.29, 1326-1336, 2008.

[30] H. C. Brinkman. The viscosity of concentrated suspensions and solutions, Journal of Chemical Physics, Vol.20, 571-581, 1952. 